\title{
Sudden Switch to Post-COVID-19 Online Classes and Cognitive Transformation of ESL
}

\section{Learners: Critical Analysis of Discourse of Fear}

\author{
* Aqsa Arshad \\ ** Madiha Afzal, Assistant Professor
}

*** Dr. Muhammad Sabboor Hussain, Assistant Professor (Corresponding Author)

\begin{abstract}
The study investigates how COVID-19 has transformed ESL learners' cognition due to the sudden shift from traditional classes to complete distant-virtual learning under the perpetual discourse of fear. The data were based on the semi-structured interviews taken by ESL learners and teachers from Punjab, Pakistan. A purposive sample of 20 female ESL learners of various social backgrounds was selected to record their lived experiences of COVID-19, which transformed their cognition. Two male and three female ESL teachers, based on purposive sampling, were also selected to investigate the reasons for the cognitive transformation of ESL learners during the pandemic. The discursive themes were explored by codifying and interpreting the qualitative data. Findings revealed that contagion had promoted bizarre linguistic forms about socio-cultural and economic transformation, which generated the discourse of fear and equally affected learner's cognition and learning process. Researchers used transformative cognitive learning as a lens to analyze the discourse of fear, which worked as a theoretical framework to portray a prevailing threat under the surveillance of COVID-19. Consequently, it resulted in the cognitive transformation of ESL learners in Pakistan due to social, psychological, economic, and technological factors. The study recommends that proper planning and support of higher authorities and better methodologies by teachers may help learners attain desirable language proficiency in such a scenario. Further, the use of neutral and contextual language by media and teachers can overcome the prevailing fear among ESL learners and maximize learning outcomes through distance or online learning.
\end{abstract}

Keywords: Cognitive, Transformation, Covid-19, Online Class, Discourse, Fear.

Introduction

Statement of the Problem

English language learning among adults has been a significant subject among ESL and SLA researchers. The present study sheds light on the cognitive transformation of English language adult female learners in the scenario of pandemic COVID-19, which forced the whole world to take a drastic shift from face to face to online classes. With the coronavirus outbreak in 2019, the whole world experienced an uncertain discourse of fear and anxiety, which affected each sphere of life, particularly, education. The sudden transformation impinged the cognitive process of ESL learners in Pakistan, due to which they confronted fear and anxiety. The language learners tried to abide by new government orders to keep the learning intact through transformative methodologies and updated socio-cultural and economic conditions. The researchers aimed to investigate the cognitive transformation of female adult English language learners in Punjab without face to face interaction. The study further tried to explore the constant discourse of fear because of COVID-19 among them. Thus, the study sets a base for future researchers interested in navigating the solutions for English language learning in critical contexts.

\section{Background}

Broadly, numerous abiding epidemics have been excruciatingly affecting human beings bringing severe threats to global public health. Correspondingly, every social and public field, including health,

\footnotetext{
* Department of English, GC Women University, Sialkot, Punjab, Pakistan Email: aqsaarshad744@gmail.com

** Department of English, GC Women University, Sialkot, Punjab, Pakistan Email: madiha.afzal@gcwus.edu.pk

*** Department of English, GC Women University, Sialkot, Punjab, Pakistan Email: saboor.hussain@gcwus.edu.pk
} 
economy, and education, had profound effects of pandemic coronavirus (also known as COVID-19). Since the pandemic bid the idea to stay home, social, and physical distancing was meant to be the only vaccine to control the spread of the virus. However, the widespread of the virus-transformed the whole world order, especially the world of education. Worldwide, institutions were sealed, and the governments appreciated online learning during the coronavirus crisis. According to the researchers, India, Pakistan, and Afghanistan were detected to be ill-prepared for online/remote learning (Khan, Niazi \& Saif, 2020). The interaction between teachers and students for the flow of knowledge and learning could only be maintained by the exclusive options of online teaching and learning. However, in the scenario of contagion, second language learning in countries like Pakistan faced social, cultural, economic, and psychological challenges affecting the cognitive process of English as a second language learners.

\section{Significance of the Study}

The present study will assist Pakistani society to comprehend the cognitive transformation of English language learners in the unpredictable situations like COVID-19. This research will help cognize young female ESL learners' language acquisition processes under the perpetual discourse of fear. Furthermore, it will assist educational administration and policymakers in devising strategies to support students with an education system that may fulfill learners' needs under critical and challenging situations like pandemics. On a broader scale, the present study will postulate the cognitive process of learning language under the constant discourse of fear, which most researchers in Pakistan have not explored earlier.

\section{Delimitations of the Study}

The present study is delimited to the followings:

- This study is based on the cognitive transformation of learning the language in the scenario of pandemic COVID-19 from face to face to online classes in an eternal discourse of fear for adult ESL female learners in Punjab, Pakistan. So, the researchers intend to exclude Young Learners (YLs) and old students from the study. This study is restricted to English as second language learners in Pakistan, who are, typically, 14-22 years old.

- The data has been taken from only female participants from the universities of Punjab, Pakistan. This delimitation might be a scope for future researchers who will be interested in working on both genders.

- Different researchers posited multiple sets of tools to investigate English as a second language learning, and this study scrutinized language learning in the discourse of fear exclusively through telephonic semi-structured interviews.

\section{Research Aims and Objectives}

This study aims to examine ESL learners' cognitive transformation in virtual classrooms and further explore the language and thought of COVID-19 to determine the discourse of fear among ESL learners, focusing on female adult (undergraduates) learners in Punjab, Pakistan.

The primary objectives of the current study are:

- To explore the extent of the discourse of fear in language and thought of ESL adult female learners since the announcement of the months-long suspension of face-to-face classes to online classes during pandemic COVID-19.

- To investigate the effects of online classes on the cognitive transformation of adult female ESL learners in the pandemic COVID-19.

\section{Research Questions}

The study intends to focus on the following research questions:

1. To what extent could discourse of fear be observed in language and thought of ESL adult female learners since the announcement of the months-long suspension of face-to-face classes to online classes during pandemic COVID-19?

2. How did online classes cause a cognitive transformation in adult female ESL learners in the pandemic COVID-19?

\section{Literature Review}

\section{COVID-19 and Socio-Political Situation}

The whole world appeared to be under the perpetual threat of getting infected since the novel coronavirus (COVID-19) outbreak outside mainland China. A bombardment of threatening images of death, long queues of people in front of pharmacies and hospitals could be viewed. In maintaining 
social-distance and covering their faces with masks, the media played a cardinal role in sensitizing people. Nevertheless, the overuse of discourse of fear begot the air of getting a virus at every place and surface (Rafi, 2020). Newspapers and media delineated a kind of chaotic discourse in corona hit countries. The world's leading newspapers reported that the virus upended routine life in all continents except Antarctica. All major cities of the world, like New York, Washington, D.C., Berlin, Rome, Wuhan, and London, were so hushed that birds' chorus could be heard (Manderson \& Levine, 2020).

Additionally, wildlife started invading human spaces. People in different countries started communicating with others from their balconies to encourage psychologically exhausted humanity (Peters, 2020). However, in such threats of contagion that twisted and transformed psychological and physical responses to ordinary interactions, teachers, internationally, were diligent in adjusting for virtual teaching, since among all other spheres of life, schools and universities were also closed.

\section{Online Classes and Cognitive Transformation}

Albeit, amid such a critical situation, students went through cognitive transformations in the learning process being in the roller coaster of fear, uncertainty, and emotional exertion. However, keeping in view the integrity of English language learning in the social texture of Pakistani society, methodologies, and techniques espoused by English language teachers were controversial in creating a productive, communicative environment to stimulate adult ESL learners' communicative competence even in traditional classrooms. Accordingly, changing learning activities into online or remote learning from face to face became more challenging and stressful for learners as most teachers were un-trained for unexpected online classes in the Pakistani scenario. In this regard, the improvement in the phenomenon of learning English demanded profound knowledge and processes of the socio-cognitive behavior of learners.

Hence, the need of a socio-cognitive approach in online classroom discourse has been emanated. Van Dijk (1977) defined discourse as processed via long and short-term memory, configuring tools for learners' perceptions and understandings (as cited in Flowerdew, 2013). In this regard, learner's thinking ability and cognitive perception might be transformed from a satisfactory classroom (face to face) into a higher risk, especially learning in online classrooms without training and less interaction. In classroom discourse, body behavior is the result of socio-cognitive functions. Empirically, researchers summed up that bodily state, bodily orientation, and emotions were affected by the cognitive process (Atkinson, 2018). From the socio-cognitive standpoint, a language is a tool for social action and interaction, which involves buying-selling, storytelling, and child-calming. Hence, despite all the verbiage, the function of discourse in certain conditions cannot be denied. Furthermore, the scenario of COVID-19 demanded a research probe to observe cognitive transformation through the discourse of fear among ESL learners.

Further, the scenario of pandemic changed the lifestyle of people all around the world. Though China was the epicenter of COVID-19 at the onset, it soon moved worldwide. The guidelines of dos and don'ts for citizens were circulated in imperative grammatical forms: strict adherence to lockdown., stay home, stay safe, stay hydrated and stay healthy and follow SOPs (Rafi, 2020). This new scenario shifted all manual processes to electronics. The governments launched e-helplines and e-learning processes. The Higher Education Commission in Pakistan supported online classes for university students. However, the whole shift from face-to-face to online classes brought a glaring cognitive transformation in Pakistan's ESL learners. In this regard, from a broader perspective, adulthood features the development of cognitive abilities, which incline towards synthesizing conflicting ideas or positions (e.-Notes Editorial, 2016).

Moreover, according to Neisser, "cognition is involved in everything a human being might do; that every psychological phenomenon is a cognitive phenomenon" (Neisser, 1967), as cited in (Houwer \& Barnes-Holmes, 2016, p. 3). Simultaneously, theorists and researchers also focused on adult learner's changing views of self and social context as an integral factor in age differences in L2 attainment (Krashen, 1981). However, this present study focused on the cognitive transformation due to the sudden switch from face to face to online learning and the effects of COVID-19 on language and thought of adult ESL female learners in Pakistan.

\section{Transformational Learning Theory}

During the scrupulous war-like condition of pandemic COVID-19, the present study used the Transformational Learning Theory (TLT) to scrutinize the cognitive transformation of ESL learners (Mezirow \& Marsick, 1978). Mezirow wrote extensively on TLT that ultimately it became his theory. 
However, it continued to be a large-scale theory in collaboration with other practitioners through a description of the application of the theory and its understanding (Mezirow, 1991). Many people availed benefits out of this theory mainly for adult educators. Indeed, it has been celebrated as being 'new andragogy and as the central adult learning theory of the day used by some transformative learning theorists' (Cranton \& Taylor, 2012). This theory has several elements, e.g., it incepts with a person being engaged in situations that cause a disorienting dilemma leading them to change or modify their meaning schemas or perspectives of meaning, being the part of their frame of reference (Mezirow, 1991). Hence, Transformational Learning Theory set forth a base to understand cognitive and emotional transformation among learners in a critical situation. Eventually, this went well with the aim of this study, which was to explore the physical, emotional, and cognitive underpinnings of this phenomenon, COVID-19, for ESL learners in Pakistan.

\section{Research Methodology}

The research is qualitative, incorporating transformative learning theory, which has been the prime focus of researchers regarding the education system. Transformational Learning Theory was first enrooted from grounded theory, and later it became prolific on its own to explore the issues related to andragogy (Mezirow, 1991). According to Mezirow (2006), transformative learning, a rational process of learning, is a metacognitive application of critical thinking within awareness, by assessing its epistemic assumptions that transform an acquired frame of reference (Wiessner \& Mezirow (2000); as cited in, (Terras, 2017). In this regard, the qualitative method aided the researchers to understand personal and individual perceptions within a contextual framework. Considering the Transformative Learning Theory an instrument for exploring cognitive transformation among ESL female learners, researchers focused on seven lenses proposed by Taylor (2007), individual perspective transformation, social transformation, socio-cultural context, power relationship, and cognitive, emotional, and behavioral transformation.

The present study tends to audit the cognitive transformation of adult female ESL learners in affiliation with the discourse of fear constructed because of pandemic contagion COVID-19. Specifically, the researchers focused on the significant changes in the English language learning process after the suspension of face to face classes and the shift to online learning in Pakistan. As a result of adverse conditions after the explosion of the novel coronavirus, the fear of death was viewed everywhere, and social distancing meant to be the overall remedy. Hence, this research focused on the qualitative approach to trace out the language and thought process of ESL learners through semistructured telephonic interviews to determine how the discourse of fear was generated during the coronavirus's pandemic and how it transformed the cognitive process of adult female ESL learners.

\section{Participants}

This study's participants are undergrads ESL learners and teachers who have been learning and teaching with a transformational platform of education under the discourse of fear in the COVID-19 scenario. The researchers decided to study the cognitive transformation on both ends, which encompassed teachers on one end and ESL learners on the other. Twenty adult female ESL learners and five teachers were selected for semi-structured interviews from all over the Punjab, predominantly from Sialkot. The data was obtained from the source of information, accessing ESL students, and taking their online semi-structured interviews. However, while appraising different participants, it was ensured to take them from different institutional and demographic backgrounds.

\section{a. $\quad$ Sampling Procedure}

Purposive sampling was preferred in which students and teachers were selected. The sample consisted of 25 participants of various backgrounds and different universities of Punjab, Pakistan, for semi-structured interviews. However, while selecting the participants and approaching them via mobile phone contacts, five learners were reluctant to give interviews, and six learners were eager to be part of the research. In this regard, the data collected from the participants with their full consent was recorded and sent back for confirmation if they wanted to add something. All the data was kept confidential, as participants were given full freedom to decide if they wanted to give an interview or not.

\section{b. Research Tool \& Data Collection}

The study employed semi-structured interviews as a research tool to collect data from ESL learners and instructors by calling each participant, recording, transcribing, and critically analyzing their views. The rationale for semi-structured interviews was to make the data exploratory and useful. 
Discursive themes were explored by codifying qualitative data through seven lenses of Transformational Learning Theory (Taylor, 2007) (1.1.4). The aim was to discern the perception and cognitive ability of the participants regarding English language learning. By taking interviews of both teachers and students, the researchers analyzed the cognitive transformation of learners in online classes critically, and an in-depth study of language and thoughts of learners, through data, helped to explore the discourse of fear. Interviews were conducted on apps like Microsoft Teams, and WhatsApp phone.

\section{Data Analysis and Findings}

The data were analyzed using the audio-recordings verbatim of participant's interviews, discursive themes of cognitive transformation, and discourse of fear. However, seven lenses of the Transformational Learning theory proposed by Taylor (2007) were used for in-depth critical analysis, as we listened and read the transcribed data several times. Initially, the interview's time consisted of one hour, but it was increased according to participants' in-depth and rich descriptions. The following figure shows how learners' cognitive transformation has been studied through the impact of the following factors:

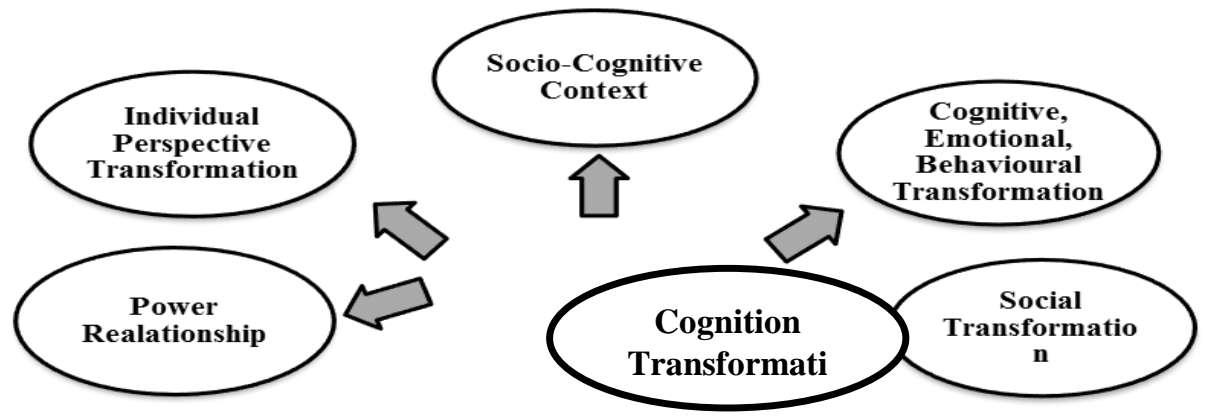

Figure 1 ESL Learners' Cognition Transformation through Transformational Lens (Taylor 2007)

Keeping in view the 'discourse processing' (Van Dijk, 2000) in the context of the situation of pandemic COVID-19, learners perceived lexical variety by media language affecting their cognitive abilities, which was comprehended dynamically and consequently, led to the production of their perception and comprehension. All the identified codes thematically constructed the development of a transformative environment educationally and socially. The whole process of transformation is illustrated in Figure 2:

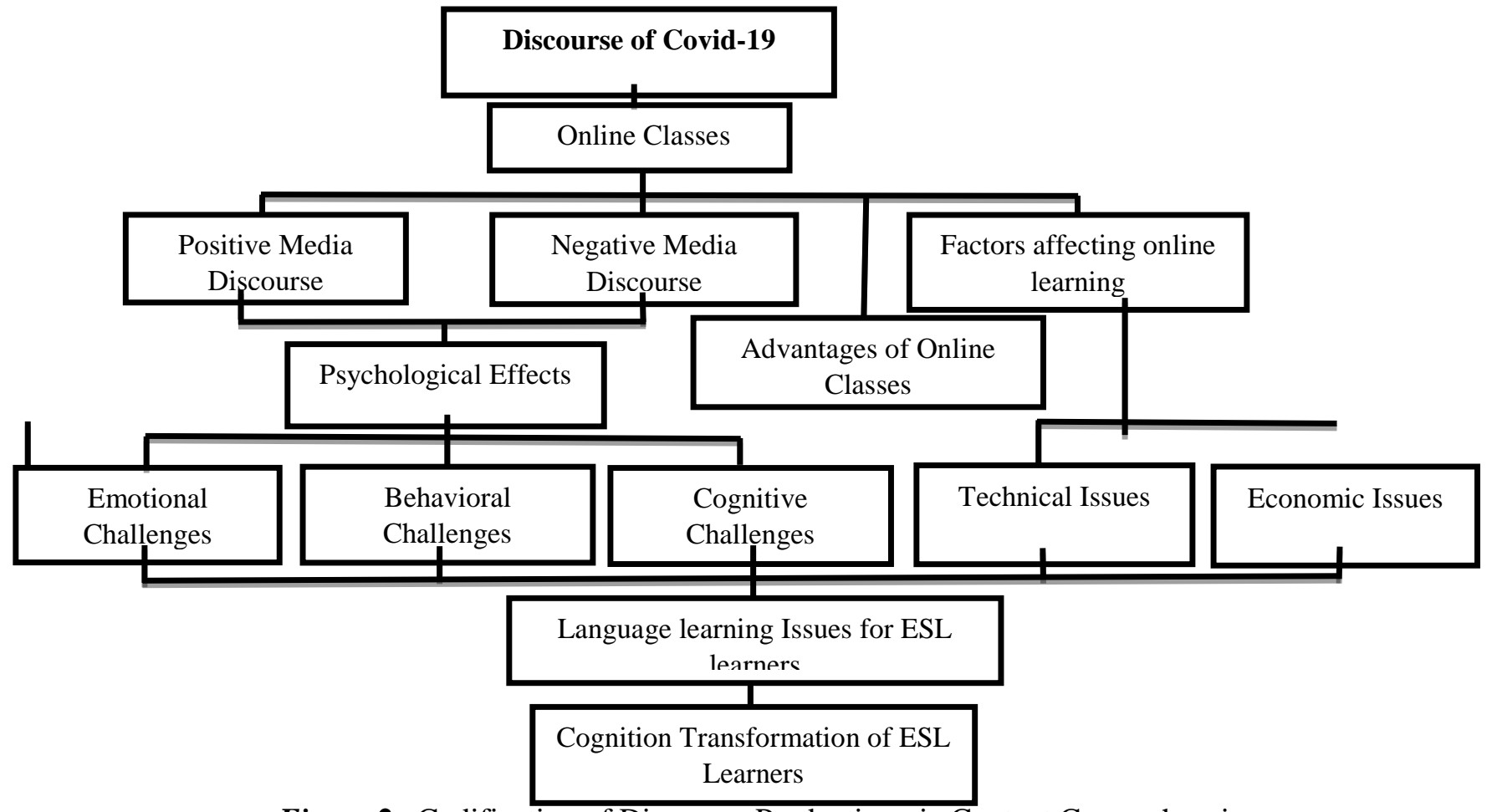

Figure 2 Codification of Discourse Production via Context Comprehension 
Analysis indicated that commonly used metonymic and metaphorical linguistic constructions used by ESL learners reflected an abrupt change in their cognition and thought processes. The discourse of COVID-19 was diagnosed in the cognition of participants through different lexicons, e.g., silent, vulnerable, and empty. ESL learners reported that their lives had transformed into new realities of the modern world, suddenly taken over by coronavirus and rampant changes in the social life. It threw them in fear of getting infected outside. Further, maximum students reported that while taking online classes, they underwent different challenges (i.e., cognitive, emotional, and behavioral), marked as psychological pressures. Besides, different factors, e.g., technical, and economic, altered their ways of thinking because of the anxiety of learning the language without interaction and practice. Apart from the factors affecting learner's cognition, various lexical items manifested to be frightening for them and they abetted an increase of lexical repertoire for ESL learners, i.e., lockdown, quarantine, pandemic, so on and so forth. Table 1 shows apparatus lexemes adopted by participants and leads towards the fundamental themes that are further categorized through a different lens of transformative learning theory.

Table 1.

Discursive Themes Derived from Coded Categories of Data

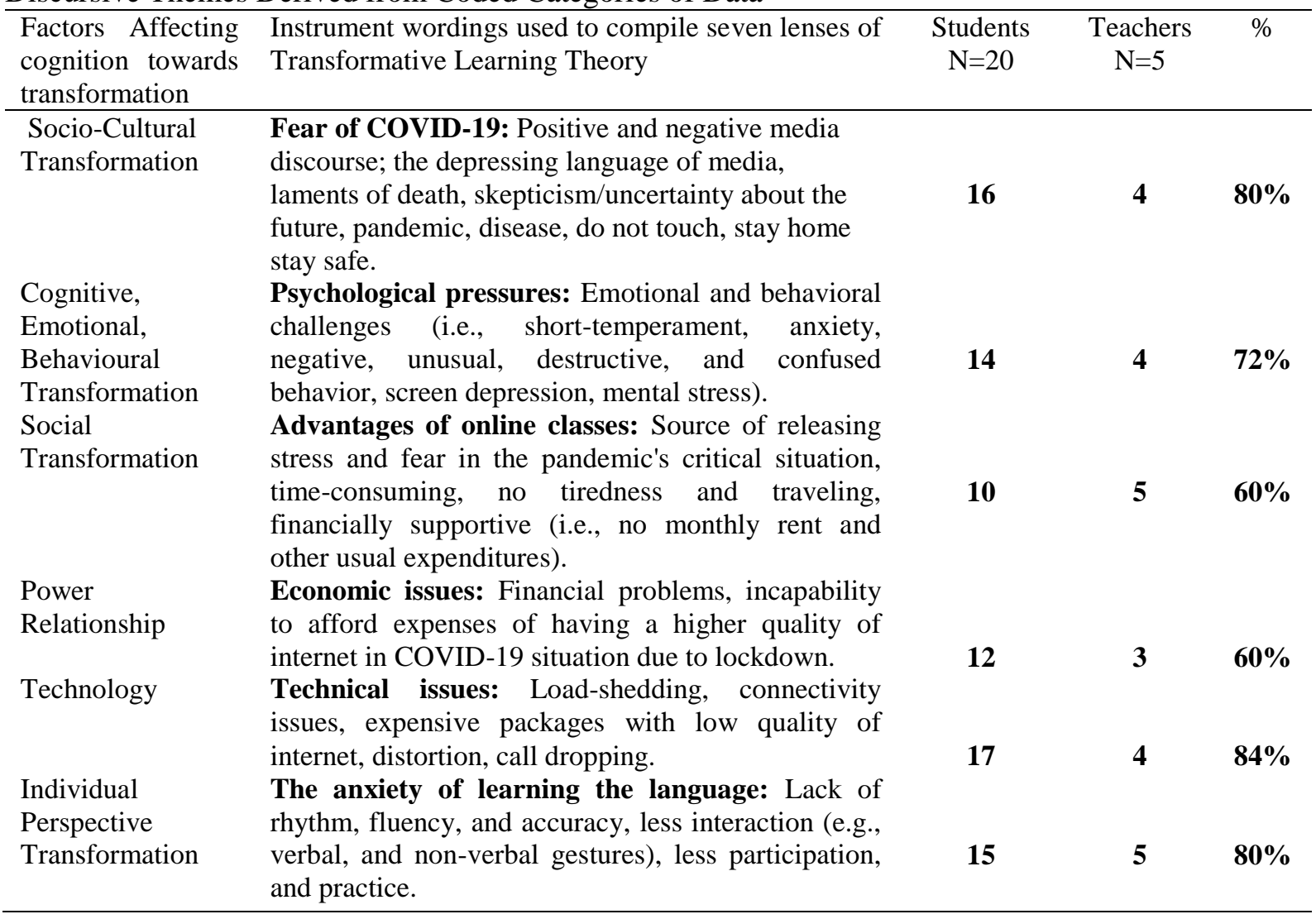

Factors Affecting ESL Learners' Transformation

Socio-Cultural Transformation

The situation of pandemic COVID-19 led to insufficient linguistic input for ESL learners in Pakistan. All the participants who recorded their responses through interviews showed a higher level of anxiety and apprehension. "There is no more hugging, no more kissing." Manderson and Levine (2020) noted that there was a shift in the culture of meeting and greeting overall. Likewise, it changed the social and cultural fabric of Pakistan. The phrase, 'social distancing' took over $r$ a healthy life. From both teachers' and students' perspectives, this intense situation had a huge impact not only on infected ones but also the caretakers of the coronavirus's victims. It significantly changed the traditional modes of teaching to mandatory online classes. All adult female learners confronted troubles in this situation as they had to endow their best to their family and studies simultaneously.

The pandemic situation proved to be challenging for students as well as for teachers. One of the respondents who teaches at BS level in the English department stated: "My learners' morale is too low; these innocent creatures...never faced such huge crises as compared to experienced people who 
might have had such experiences". Moreover, almost $80 \%$ of all respondents showed fear in their language while taking interviews, which is presented below in Table 2.

Table 2

Discourse of Fear (S: Student, T: Teacher)

\begin{tabular}{ll}
\hline Fear of COVID-19 & Instrument Wordings/ propositions \\
\hline Uncertainty about & S: "I feel like we are going to die... don't know what is going to happen in the future". \\
Future & S: "It is horrifying and depressing to listen to the news about deaths all the time." \\
Fear of losing lives & S: "I'm tired of washing hands and using sanitizer and all that stuff." \\
Instructions to & T: "We are doing much care as doctors and newscasters say so, but still, there is no \\
follow & control in Corona." \\
& T: "This is very sad to have a specific distance from beloved ones." \\
& We can't go anywhere because of too many patients in our town".
\end{tabular}

Further, the analyses of interviews conspicuously manifested that even the positive media discourse according to the situation used by social media harmed the cognition of learners as the phrases like "stay home stay safe," "Darna nahi learn hy", "don't touch" proved to be double-edged and distressing for ESL learners who never encountered crisis like coronavirus. This social, cultural, and economic change severely affected people resulting in the cognitive transformation of ESL learners under the constant discourse of fear.

\section{Cognitive, Emotional and Behavioural Transformation}

Psychological pressure on adult ESL female learners considering the emotional, behavioral, and cognitive transformation was determined by the terms presented in Table 1. Learners' behaviors, emotions, and cognitive abilities transformed into overthinking and perceiving the world more negatively. Keeping in view the discursive practices in the context of socio-cultural transformation, ESL learners faced such obstacles when they did not attain enough and relevant sessions to learn the language. From teachers' perspectives, online classes agitated students as they always appeared with unexpected issues under contagion.

In addition to the fear of affliction, learners could not give appropriate attention to their health, as most of them frequently worked on mobile phones, which caused health issues. Students' perspectives on contagion and online classes seemed more critical than those of the teachers. However, one of the teachers' stated: "Learners need higher cognitive ability to deal with more multidimensional learning tasks". The following table presents the psychological issues faced by teachers and learners.

Table 3 Psychological Pressures

\begin{tabular}{ll}
\hline Psychological Pressures & propositions towards transformation \\
\hline Destructive Behaviour & S: "I don't know why my behavior is getting bad and bad staying home for so many \\
Short temperedness & times". \\
Screen Depression & S: "I don't talk to anyone and get angry at too many little things". \\
& T: "Students are too tired of using mobile and laptop all the time as the screen \\
Health issues & causes depression. It is complained about by almost all the students". \\
& T: "Every day, there are lots of absentees in the class because of sickness and other \\
Mental Stress & S: I'm suffering from headache; weak eyesight and my dark circles are now more \\
& prominent". \\
& S: "I can't handle it anymore to take care of my family, and in this house chores, it \\
& is very difficult to get time to study".
\end{tabular}

The change in behavior was another factor that exerted influence on the cognition of learners. Due to the change in the external lockdown environment, people were bound to stay at homes, which was reported depressing. Moreover, it caused short temperedness, negative, confusing, and destructive behavior among ESL learners. Furthermore, the constant screen beholding of mobile and laptop for taking online classes and making daily assignments caused severe health problems, i.e., headache, backache, weak eyesight, and many others. Further, there was always an extra set of household responsibilities for female students. For instance, they were to take care of family members, vulnerable to getting infected by COVID-19. So, it became hard for female adult learners to pay proper attention to their studies. Hence, this constant and static environment of COVID-19 affected adult ESL learner's cognitive processes altogether and transformed it drastically. 


\section{Social Transformation}

Apart from the psychological problems, $60 \%$ of the participants, including ten students and five teachers, reported the positive side of online classes as they proved to be advantageous in so many ways as instrumented in table 1 . Most of the students, as well as teachers, agreed with the continuity of online classes because it was the most constructive way to consume time, was financially relaxing, and was a source of psychological diversion in the pandemic. Teachers took online classes positively. Most of the teachers enjoyed online teaching considering it the new normal. Almost all teachers supported the idea of hybrid classes after resuming traditional classes. They seemed satisfied with the practicality and usefulness of online teaching and learning. Many students living in far-flung areas also supported the online mode of learning. From such students' perspectives, online learning was beneficial as they used to get tired of traveling otherwise. Moreover, looking at the financial side, learners acknowledged that online learning cut short their expenses of fares and hostel fee as presented below in Table 4:

\section{Table 4}

Advantages of Online Classes

\begin{tabular}{|c|c|}
\hline $\begin{array}{l}\text { Advantages of Online } \\
\text { Classes }\end{array}$ & propositions/ instrument wordings \\
\hline Source of releasing stress & $\begin{array}{l}\text { S: "This is the only way that I can stay away from this bad situation of } \\
\text { corona". } \\
\text { T: I think this is a very great step for HEC to continue with online classes in } \\
\text { this modern world of technology because it has been fun to teach living } \\
\text { comfort zones". }\end{array}$ \\
\hline Time-consumption & $\begin{array}{l}\text { S: "Online classes are good as I have too much time to study now". } \\
\text { T: Online classes give the quality time to teachers and students to give time to } \\
\text { each and everything regarding their studies". } \\
\text { T: "We had to travel a lot in F } 2 F \text { classes, but I would say that we are getting }\end{array}$ \\
\hline No tiredness and traveling & $\begin{array}{l}\text { so many benefits from online classes". } \\
\text { S: "I feel comfortable in online classes because there is no traveling and I'm } \\
\text { too far from my university and have to travel a lot". } \\
\text { S: "I'm enjoying online classes living in my comfort zone, and there is no }\end{array}$ \\
\hline Financially supportive & $\begin{array}{l}\text { tiredness". } \\
\text { S: "In this lockdown, online classes are beneficial because we don't have to } \\
\text { pay monthly rent". }\end{array}$ \\
\hline
\end{tabular}

\section{Power Relationship}

From the lens of power relations, a cogent percussion for Pakistan's social classes, half of the learners encountered economic crisis in the COVID-19 scenario, as $48 \%$ of all the responses, including 12 students and three teachers, reported financial issues. One of the teachers commented on Pakistan's social classes that most students belonged to the upper-lower and lower-middle classes. The families making their earnings with daily wages suffered the most. In such conditions, some learners complained that it became hard to make both ends meet, let alone affording the expenses of Wi-Fi and internet packages. The students belonging to economically stable families tended to be relaxed to encounter online classes. But the situation was not very convenient for un-stable social classes. Thus, under the perpetual discourse of fear during the lockdown, learners faced the rampant risk of losing previous proficiency of the English language, without appropriate interaction and classroom environment (Granados, 2020). The sense of fear because of economic and technical issues was observed in the data gathered from interviewers:

\section{Table 5}

Economic and Technical Issues

\begin{tabular}{|c|c|}
\hline $\begin{array}{l}\text { Economic \& Technical } \\
\text { Issues }\end{array}$ & instrument wordings/ propositions \\
\hline Economic Issues & $\begin{array}{l}\text { S: "We are living in a town which is sealed for a month because of Coronavirus } \\
\text { patients, and it is difficult to go out to earn money in lockdown to bear the } \\
\text { expenses of laptop or smartphone". } \\
\text { T: Students in Pakistan face more financial problems than the teachers; that's } \\
\text { because online classes are no more than just a little change for teachers, which is } \\
\text { more comfortable". }\end{array}$ \\
\hline Technical Issues & S: "I cannot annoy my family to buy a laptop for presentations and assignments" \\
\hline
\end{tabular}


when I know that it is difficult in lockdown".

$S:$ :In every class, my call drops, and my concepts remain unclear...".

S: "I have Wi-Fi, but every time I'm always worried about electricity".

T: Sometimes, it is very annoying that you lose connection and speak continuously, then you get to know that students didn't listen to even a single word".

Technical problems also proved to be an impeding factor for the learning process. The data showed that learners faced obstruction in taking online classes with the required ease and comfort due to lockdown and fear of getting infected by the coronavirus. Furthermore, it caused anxiety among learners, as shown in the instrument wordings presented in Table 5. The technical side of the online program was considered challenging for ESL learners and teachers, as $84 \%$ of the participants, including 17 students and four teachers, reported issues like the connection problem, expensive packages with low quality of internet, weak signals, distortion, and load-shedding. Though, the students who possessed an extra-bandwidth of internet facilities observed to get benefits, but those who were unable to get proper internet packages and were supposed to use expensive packages with low-quality service, reported the failures of online classes transforming learning into burden and anxiety. Load shedding was another significant hampering factor reported by $40 \%$ of respondents. This segregated learners into two categories, i.e., haven and have not, which subsequently determined the cognitive transformation of learners. Most teachers and students alleged the power breakdown experiences and reduced internet speed while taking online classes.

\section{Individual Perspective Transformation}

From an individual perspective on transformation, of all 25 interviewees, $76 \%$ of responses, including 15 students and five teachers, revolved around the anxiety of learning the language. A high level of anxiety about students' learning language was divulged by teachers, which led researchers to inspect teachers' teaching experiences and ages. The analysis revealed that teachers beyond 45 seemed a bit reluctant to embrace the change. In this scenario, where online classes were luxurious for some teachers considering the technological advancements, some teachers taught several years in traditional (F2F) mode and were not fully equipped for virtual teaching. They considered them ineffectual for getting enough output from learners. As one of the teachers' response was: "I feel that F2F learning allows alive interaction between a learner and an instructor which is now lacking properly".

Almost all learners came across troubles while learning a second language that was not spoken and used in their surroundings. They faced problems in this regard as they participated less in online classes and felt less motivated. Many students wanted individual attention, which lacked in online classes. From teachers' perspectives, learners were ready to face new challenges of the modern world, but the sudden attack of COVID-19 was a total setback to their learning capabilities. Besides, individual traits and individual challenges for each learner relatively increased the risks of learning the English language via online interaction. Table-6 displays the everyday problems of ESL learners, generally.

Table 6

Common Problems

\begin{tabular}{ll}
\hline Problems & propositions towards transformation \\
\hline Less practice & T: "All of our students speak either Urdu or Punjabi in homes, English is their \\
& second language, and they get a very short time to speak English in online \\
classes. & \\
S: "In university, I used to speak in English with my friends and teachers, there \\
was an interaction which is lacking now in online classes". \\
T: "In university, I was a very responsive student and used to participate in \\
every class". \\
S: I'm too lazy in online classes because I need motivation, which I could only \\
get from my teachers' attention towards me". \\
S: "We listen to the audios... don't video chat in online classes, and without eye \\
contact, it is difficult to learn English because of no interaction". \\
S: "In the online class, the teacher can only interact with one or two persons". \\
T: There are limitations regarding interaction in online classes, and the true \\
Lessence of teaching is being lost". \\
"If we don't practice...I don't think we would be able to speak publicly".
\end{tabular}


Online classes were observed to be far from optimal somehow since learners affirmed the paucity of fluency that they had already attained before the pandemic. Moreover, a teacher respondent stated: "We usually encounter difficulties even in F2F classes, so when it comes to online classes, the problem manifolds related to the learning process". According to ESL learners, they were at the stage of finding themselves with better career options, but COVID-19 turned everything down.

\section{Discussion}

The study found out that online classes, a drastic change in methodology, and the fear of COVID-19 pandemic, changed the recognition of learners and induced them towards ambivalence and uncertainty. However, due to the transformation in Pakistan's socio-cultural aspects, the findings divulged that the female learners confronted difficulty in managing households and studies, which led them to depression and emerged as a massive barrier in their learning process. Participants, learners, and teachers were agitated by the online system under the pandemic threat. It was revealed that a sudden change impacted every sphere of life, including practical, cognitive, and emotional. Students showed anxiety and uncertainty about their future regarding language learning, the fundamental need for their learning process, and examined at every level of obligation. According to Parisi, the students of ESL, populated in community colleges faced many challenges. "Students often live in linguistically isolated communities and are in effect of English as foreign language (EFL) students rather than ESL students" (Drake, 2014; Hardman, 1999, as cited in (Parisi, 2020, p. 1).

Moreover, female ESL learners were disturbed by the new system without training and confronted multiple issues. Teachers were equally disturbed by the pandemic situation but satisfied to some extent by the online system because of the facilities accessible for them. But the learners lacked them due to their social backgrounds. A needed interaction could not be appropriately provided to students, which affected their learning process. As Murugaiah (2010) pointed out, collaborative and interactive tools are crucial in online learning, as learners are separated geographically and temporally, which led them to be disciplined and motivated to learn on their own (Murugaiah, 2010). In this regard, learners in Pakistan were not motivated to learn independently under a firm grip of certainty about various challenges of the prevailing situation and uncertainty about the consequences due to which they remained confused. Likewise, student-teacher interaction in ESL classes is the most dominant factor, and sometimes even more influential factors show up, such as personal, motivation, anxiety, input, and output skills, setting, and time commitment. In this regard, the study found out that ESL learners could not master the language without an appropriate interaction in the online classes.

The findings of this study revealed significant problems confronted by most of the students. In the online system, some changes are required in the educational policies considering the problems and demands of students. Without proper planning and training, ESL learners were found anxietyridden in the online learning system, as they declared it more confusing, less interactive, and incompatible in many ways.

\section{Conclusion and Recommendations}

Coronavirus's ubiquitous influence was felt by everybody around the world, and the fear of its omnipresence upended the normal life, leaving everything topsy-turvy. The war rhetoric, negative expressions, and intense terms transformed the thought and behavior of ESL learners. According to Lee and VanPatten1g (2013), "features of proper language... can only make their way into the learner's mental representation of the language system if they have been linked to some kind of realworld meaning" (p.27). However, widespread COVID-19 transformed the real world's meaning with perpetuated fear and changed mental representations of language learners entirely.

A timely decision of the continuing learning process through online classes was taken up by the government of Pakistan, but it decreased in-class communication and task-based activities, which are the essence of learning a second language. Moreover, the greeting and meeting culture was taken over by outlandish linguistic forms, social distancing, and social isolation. In such a scenario, people started feeling aliens to each other. It produced sinophobia (Rafi, 2020) among people and put learning language processes at stake.

Moreover, students began to move towards irrational responses of anxiety, panic, and hatred created most probably at a subconscious level through the discourse of fear. It shifted all responsibility on language teachers who were not adequately trained to teach language under such conditions. It ultimately led to teacher-oriented classes in the Pakistani scenario. American Council on the Teaching of Foreign Language (ACTFL, 2012), recommends that the target language be used at 
least $90 \%$ of class time by both teachers and students. Rather, teachers talk-time should be less than learners who should communicate with each other to complete task-based activities. Through the lens of Transformative Learning Theory, in this study, researchers tried to bring forth social, psychological, individual, and cultural issues and power relations that modified the learning patterns of ESL learners in Pakistan.

However, this research recommends some solutions to cope with severe challenges.

- Better training of teachers and speculations for online language teaching methodologies can minimize the risk of losing language proficiency in learners.

- Teachers' positive behavior and compassionate talk can overcome the fear of contagion among learners.

- $\quad$ Some solid steps are required from the Government of Pakistan and the Higher Education Commission to provide better and cheap internet facilities to students to cope with the education crisis in the pandemic.

- According to Rafi (2020), COVID-19 is such a massive crisis and demands the use of language, which could bring social solidarity, maintenance of proper language learning than to vilify learners to achieve their desirable proficiency. Here, researchers suggest that careful use of language by media and teachers may decrease the sense of fear among learners.

Hence, the study invites future researchers to discover further the issues and problems related to English language learning in an online scenario in different contexts. Moreover, they may go indepth and provide solutions that how online classes can be more well organized for English language learners.

Reference

ACTFL. (2010, May 22). Use of the target language in the classroom. Retrieved from http://www.actfl.org/i4a/pages/index.cfm?pageid=5151

Atkinson, D. (2018, April). A Socio-cognitive Approach to Second Language Acquisition: How mind, body, and world work together in learning additional languages. Retrieved from Research Gate:

https://www.researchgate.net/publication/324171342_A_Sociocognitive_Approach_to_Secon d_Language_Acquisition

Cranston, P., \& Taylor, E. (2012). Transformative learning theory. In E. Taylor, \& P. Cranton, The handbook of Transformative Learning: Theory, Research, and practice (pp. 3-22). San Francisco, CA: Jossy-Bass.

Dirkx, M. J. (1998). Transformative learning theory in the practice of adult education: An Overview. PAACE Journal of Lifelong Learning, 1-14.

E-Notes Editorial. (2016). What is the difference between adolescence and adulthood? Retrieved from http://www.enotes.com/homework-help/what-difference-adolescence-adulthood-540150. Accessed June 9, 2020

Flowerdew, J. (2013). Critical Discourse Analysis. Discourse in English Language Education (p. 181). USA \& Canada: Routledge.

Granados, A. (2020). How is COVID-19 affecting ESL students? Retrieved from http://www.ednc.org/how-is-COVID-19-affecting-esl-students/

Houwer, J. D., \& Barnes-Holmes, Y. (2016). What is cognition? A functional-cognitive perspective.

Khan, A. A., Niazi, S., \& Saif, S. K. (2020). Universities unprepared for switch to remote learning. Retrieved from University World News: http://www.universityworldnews.com/postmobile.php?story=20200326141547229

Krashen, S. (1981). Second language acquisition and Second language learning. Oxford: Pergamon Press.

Lee, J. F., \& VanPatteng, B. (2003). Making communicative language teaching happen (2nd ed.). New York, NY: McGraw-Hill.

Manderson, L., \& Levine, S. (2020). COVID-19, risk, fear, and fallout. Medical Anthropology, DOI: 10.1080/01459740.2020.1746301Mezirow, J. (1991). Transformative dimensions of adult learning. San Francisco, CA: Joss-Bass.

Mezirow, J., \& Marsick, V. (1978). Education for Perspective transformation: Women's re-entry programs in community college. New York: NY: Teachers College, Columbia University. 
Murugaiah, T. (2010). Development of interactive or reflective learning among Malaysian online distant learners: An ESL instructor's experience.

Peters, M. A. (2020). Love and social distancing in time of COVID-19: The philosophy and literature of pandemic. Educational Philosophy and Theory.

Parisi, J. A. (2020). Self-directed learning practices in ESL: How beginning adult Latin English language learners can increase learning outcomes.

Rafi, M. S. (2020). Language of COVID-19: Discourse of Fear and Sinophobia. Social Sciences and Humanities Open, 18.

Taylor, E. W. (2007). An update of transformative learning theory: A critical review of the empirical research (1999-2005). International Journal of Lifelong Education, 26 (2), 173-191.

Terras, K. (2017). Transforming the teacher: Examining personal transformations of faculty redesigning courses from face-to-face to online 